\section{A mother-child secure attachment to prevent interpersonal violence among young people}

\section{Uma relação de apego mãe-filho com qualidade para prevenir a violência entre os jovens}

Marc Bigras 1

Maria Aparecida Crepaldi 2

Maria Luiza Carvalho de Lima 3

\footnotetext{
1 Departament of Psychology. University of Québec. Montreal, Canadá. E-mail: bigras.marc@uqam.ca

2 Universidade Federal de Santa Catarina. Florianópolis, SC, Brasil.

3 Centro de Pesquisas Aggeu Magalhães. Fundação Oswaldo Cruz. Recife, PE, Brasil
}

\begin{abstract}
There is a growing conviction among researchers and stakeholders that youth violence is often a result of the absence, or the disturbance, or even the disruption of significant relationships with adults. In this article, we propose to apply the mother-child attachment theory to an intervention of public health in order to prevent personal and social damages as consequences of youth violence. Many consider indeed that this theory is mature enough for social innovations and can lead to a light but structured program in support to young parents that favors the outbreak of basic necessary elements for the harmonious socialization of their children.
\end{abstract}

Key words Public health, Violence

\section{Resumo}

Há uma crescente convicção entre os pesquisadores e interessados no estudo da violência de que a violência em jovens é, muitas vezes, resultado da ausência, da perturbação, ou mesmo do rompimento de relações significativas com os adultos. Neste artigo, propomos a aplicação da teoria do apego mãe-filho para fundamentar a intervenção em saúde pública, a fim de evitar danos pessoais e sociais como consequências da violência juvenil. Muitos consideram o potencial consistente desta teoria para implementar inovações sociais e fomentar programas claros e estruturados para apoiar os pais jovens a fornecerem aos seus filhos uma socialização consistente e harmônica.

Palavras-chave Saúde pública, Violência 


\section{Introduction}

According to the World Health Organization (WHO), interpersonal violence is one of the main causes of morbidity and mortality among young people in the world. The WHO notes, however, that researchers and clinicians have found very incomplete answers to important questions about the causes of this violence and the ways to counter it: what motivates young people to inflict serious physical injuries, even fatal, to their family members or from their community? What drives parents to psychological or physical violence that may permanently affect the future of their own children? What are the personal, interpersonal or environmental factors which explain such violence? How could we reduce the prevalence of mental and physical disorders associated to the trauma of violence? 1

According to an analysis of the economic impacts, violence is very expensive in terms of health services and social services and these costs appear outrageous when considering that usually the responses concerning violence damage are ineffective. 2 To face the serious consequences of violence and the failures of our interventions, we should therefore readjust an often moralizing theory of the problem and revise repressive solutions which aim mostly to flush out and punish the guilty ones. Following WHO's guidelines, we propose here to consider violence as a public health issue, which would broaden the analysis of strictly individual causes to observable and modifiable determinants of the person-environment process related to violence.

More precisely, in this article, for better understanding and fighting against the negative effects of violence, we propose to make a review of the studies that emphasize precisely the person-environment processes called «proximal », which are observed more frequently in the family. Those proximal processes are indeed considered as the motor of human development, because they trace the differentiated course of the skills acquisition or the dysfunctions over the challenges posed by the environment. ${ }^{3}$ One of the best known processes to understand specifically the acquisition of social skills in young people or, instead, the dysfunctions related to interpersonal violence, is the one of parent-child attachment. We will see that the link of attachment which binds in a particular way a child to an adult, usually the mother, could be a key for the comprehension of interpersonal violence and, therefore, for the strategy to promote a peaceful social environment. For a better comprehension we use, throughout this text, the term 'mother-child' attachment for two reasons.
First, since the attachment relationship characterizes neither the mother nor the child, but rather the quality of the process between them, we then labeled this relationship as 'mother-child'. Second, =we know that any adult attentive on a regular basis to the needs of the baby during the first year of life may become the main attachment figure, but this person usually is the mother.

\section{The adult-young relationship and violence}

There is a growing conviction among researchers and stakeholders that youth violence is often a result of the absence, or the disturbance, or even the disruption of significant relationships with adults. ${ }^{4-5}$ Moreover, research on populational samples concludes almost consensually that adults strongly contribute to youth's social integration thanks to: a) the creation of a sense of confidence in the self and in others, b) the development of required skills to deal with life in society, such as the regulation of emotions or the empathy and c) the development of required cognitive skills to deal with the complex world of school and work, as planning and paying attention to the task, etc. 6 This research promptly admits that a young person is an active agent in its own development, but it also points out that the adult's role is central, either by the importance of resources that he/she may offer to the young people or because of his/her social responsibility with them.

Knowledge mainly concerns the role of parents (much frequently the mother) in the normal course of youth, but we know few things about the protective effect of adults, for example, on the persistence or abandonment of a violent career. The features of this «protective effect of adults» are so little defined that it is still hard to teach the principles and the proficiency of this effect to parents, students or professionals concerned with the needs of violent young people or the assaulted ones. How to establish a significant relationship with a young person and an adult? Does this relationship have the same nature as it is experienced with a parent, teacher, doctor or social worker? Is it the kind of supervising, the quality of models offered to youth or rather the relationships between adults and young based on confidence that count? The mother-child attachment theory may have answers to some of these questions.

\section{Mother-child attachment and violence}

The attachment theory has succeeded, over the last fifty years, in characterizing the fundamental relationship established between the parent and his/her 
child. 7,8 These long-term works have inspired protocols of family evaluation and intervention, which are now well proven for youth social integration. ${ }^{9}$ For example, the attachment theory teaches students and professionals that we must distinguish the concept of interaction from the concept of relationship, because this last one reflects somehow the history of interactions between parent and child. This experience would better organize future parent-child interactions, that is to say, it lays relational schemes called 'internal-working model (IWM)' that the growing child tends to generalize to other social partners such as teachers, friends, working colleagues, lovers, etc. It also teaches that the implementations of the theory are successful when it comes to simulate relationships between babies and their parents or with adoptive parents or teachers. Yet, experiences on the implementation of the attachment theory with violent young people are still in deployment, which requires a consolidation of the university-community expertise in order to ensure the implementations that reflect on advanced research in this field. Despite the limitation, here are some evidences that can inspire programs to stimulate a quality motherchild relationship in favor of more peaceful societies:

\section{The parent-child attachment is a proximal} process

Sustained interactions with an attentive adult enable the infant's genotype to deploy in a maximized phenotype for a better adaptation to different physical and social environments. The adult role in this stage of the child's life consists in decoding and responding to his/her attachment behaviors (crying, smiling, grabbing, crawling). Thanks to phylogenesis in humans, attachment behaviors rarely change from a child to another: the survival of the newborn depends indeed a lot on these behaviors to trigger the proximity and care of an adult. What vary are the parental answers to these demands of care and protection according to psychological of the caregiver, his/her family and social conditions. The mother-child attachment, or the product of the attachment behaviors and the parental answer, develops early in the child's life; that is an opportunity because this experience may leave a lasting mark. Decades of research findings suggest that in case of parental care default a quick intervention is necessary and that a support to helpless parents in front of the attachment behaviors of the infant could prevent unfavorable conditions for the child's physical and mental health.

\section{Parental sensitivity}

Parental sensitivity is characterized by quick, stable and consistent answers to demands of care and protection demonstrated by the child. 10 The infant's needs do not require expensive investments or complex cognitive, social or emotional interactions. Actually, a stable and careful response is enough, even minimal, to requests of proximity, food, warmth of the baby. In this sense, parental contribution to the attachment system is relatively simple and it seems affordable for most of the adults. This does not mean that parents are able to offer these minimal conditions in all circumstances. For example, the instability of care is more common when parents must work out of the family's environment, and when it forces them to entrust the baby care to substitutes. Several research data, although controversial, suggest that submitting a low-age child to extended services of substitute care could cause a negative effect on his/her development, especially if that consists in exposing the child to multiple attachment figures and, consequently, unstable ones. ${ }^{11}$ In any of these results, studies show a consensus on the definition of parental sensitivity, that is to say, on what is minimally necessary for the infant's full development. This gives us good targets for the promotion of maternal sensitivity and security base that such care provides to young children.

The child's confidence in self and others and exploration abilities are positive consequences of maternal sensitivity. More recent studies suggest also gains for the child at the level of neurological maturation, but most of the corpus of the attachment theory emphasizes primarily its advantages in socioaffective terms. ${ }^{6}$ Precisely, we observe that fast, stable and consistent maternal answers to the child's attachment behaviors enables him/her to find in this experience a balance towards this attachment system that provides him/her some security, but also in the system of the exploration behavior. The activation of these two systems and their balance occur throughout life, but more easily observed in a 12 to 18 months child, a stage of development in which the bond with the mother is stabilized and the child still expresses the need of a safety base to face the world around him/her. For example, the infant will actively seek for the presence of his/her mother (also called 'secure base') when in a potentially dangerous situation for $\mathrm{him} / \mathrm{her}$ (a situation that triggers off the attachment system), then, instantly reassured in contact with his/her mother (that triggers off the exploration system), we will see him/her back and enthusiastic to activities of exploration in the world 
of objects and people. According, in one hand, to the source and the intensity of discomfort and, on the other hand, the proximity of the secure base, the adjustment of these two behavior systems is called pattern of attachment. ${ }^{12}$ This balance is in fact the expression of a behavioral regulation capacity driven by an internal-working model (IWM). IWM is a type of socio-emotional-cognitive scheme built from the early experience of the child in which a sensitive response to his/her needs makes him/her feel that the entourage is rewarding and predictable and that he/she deserves to be part of it. An IWM is relatively stable and it organizes the child behaviors for increasingly complex social challenges. For example, the attachment pattern described above wherein the infant finds a balance between the need of safety and needs of exploration (the 'secure attachment') is related to an IWM of which we can observe that, since preschool age, the child tends to trust peers and adults. The child exchanges straight off his/her personal and immediate needs for a partnership with an adult, which is favorable to the achievement of common and long term goals. The IWM of a secure mother-child attachment would be at the basis of the harmonious socialization process in humans.

Longitudinal studies conducted in several laboratories around the world are quite convincing about the advantages of the secure pattern of attachment (secure $\sim 65 \%$ of the population) for the development of the child's social skills. Studies on several patterns of imbalance among behavior systems, one called anxious-avoidant (insecure-avoidant $\sim 10 \%$ of the population) and the other anxious-resistant (or insecure-resistant $\sim 5 \%$ of the population) are however more mixed as to their long-term negative impacts, but they seem to point out that these anxiogenic patterns would be associated with greater social difficulties in children, such as aggression and shyness, especially when they are combined with other conditions of risk such as poverty and parents divorce. Much clear however are findings concerning negative consequences on a child's mental health from an attachment pattern called disorganized (disoriented-disorganized, 10 to $15 \%$ of the population) found mostly in abusive families. ${ }^{13}$ Briefly, long-term longitudinal studies demonstrate a higher risk of mental health problems and antisocial behaviors for young people and adults who established an insecure or disorganized attachment in childhood. Experimental or quasi-experimental studies reinforce, in addition, the idea of a causality between the quality of mother-child attachment and a variety of behaviors of social skills or, in contrast, antisocial behaviors in young people. These studies, which are in fact evaluations of stimulation programs of attachment during childhood, confirm that support services for young parents, usually limited to a few hours, could have a beneficial effect on the attachment link to short term and, consequently, on the child's social skills in longer term. ${ }^{14}$ Those stimulation programs often take place in the child's first year of life and are usually composed by three parts: a) teaching the needs and development of the infant, for example, through activities of decoding the baby's signals; b) exchanging particular difficulties of the family's day to day; c) creating strategies to break down parents' isolation. ${ }^{15}$ In short, in the field of developmental psychology, the accuracy and robustness of these results suggest that promoting a secure mother-child attachment relationship could contribute to a strategy of public health which aims for promoting youth's skills that are necessary for a peaceful social life.

\section{Conclusions}

Research on mother-child attachment is encouraging for a better understanding of the social skill development among young people and also for better actions to reduce the damage of interpersonal violence in the family and the community. These studies suggest that simple interventions with young parents would promote a secure mother-child attachment and would help to build in the child the schemes (IWM) required for his/her social integration in longer term. The infant who experiences a grateful and predictable environment builds an IWM that coordinates, throughout his/her development, the awareness of others' point of view and the establishment of cooperative strategies for solving interpersonal issues and achieving common goals.

Another significant advantage of the stimulation programs of attachment is that parents reported to feel less depressed, less stressed and more competent after their participation. ${ }^{9}$ These are ingredients that contribute to hold positive effects of prevention on children themselves. It reminds that prevention must accomplish an empowerment philosophy which consists in entrusting parents to analyze their problems and also search for solutions. Therefore, it is important that parents come out bigger and better integrated into their communities as a result of their participation in prevention programs of interpersonal violence. These conclusions are not banal when we remember that research on the mother's role has very frequently led to interpretations to make mothers 
feel guilty. Works on the implementation of the attachment theory have always advocated instead that any mature person may become an attachment figure for the child and that family and environmental aspects would determine the relationship that takes shape between an adult and a child.

Though we know that other adults besides the mother can play supplementary and complementary roles for social integration of young people, science has, on the other hand, little to say for characterizing this kind of relationship. To validate the notion of «relationship» between «non-parents» adults and young people, it would probably be necessary to rely on other theories' contribution and other disciplines than developmental psychology. For example, several studies in human ethology, in education and clinical psychology have already leaned on notions such as the relationship of father-child activation, 16 the educational 'teacher-student' 17 relationship or on the therapist-young alliance18; so many relationships to create without which social learning would lead to superficial gains for young people. However, the potential execution of these research fields is not an easy pathway to achievement. 19 For the moment, we must especially rely on the strength of mother-child attachment theory to promote more peaceful interpersonal relationships.

Violence is a complex phenomenon and it would be too audacious to conclude that an intervention of a few hours offered to young parents could overcome decades, or even centuries, of violent cultures. We shall mention the possibility that the most merciless violence could be the result of social inequalities fueled by ignorant institutions or who despise the population's needs. What should be the point of view and responsibility of public health proponents face to the possibility of this institutional violence? Most of the stimulation programs of mother-child attachment include accompanying components with the aim of countering eventual effects of social exclusion for parents and their children. But, those efforts could be seriously compromised by institutional abuse and research does not enlighten us much about the real hope of public health interventions in this context. The authors of this paper defend that parents can protect their children from ambient aggressions by providing, despite everything, the resources minimally necessary for the child. Unveiled by science, we believe that the process of mother-child attachment provides to parents, health stakeholders and social services a lever to prevent the negative effects of interpersonal violence. We believe it is our role as a researcher, clinician, or community member to be part of this wide range of resources available for the parent to protect their child.

\section{References}

1. Organisation mondiale de la santé. Rapport mondial sur la violence et la santé. Genève; 2002. p. 404.

2. Organisation mondiale de la santé. The economic dimension of interpersonal violence. Genève; 2004.

3. Bronfenbrenner U, Evans GW. Developmental science in the 21 st century: emerging theoretical models, research designs, and empirical findings. Social Development. 2000; 9: 115-25.

4. Le Blanc M, Ouimet M, Szabo D. Traité de criminologie empirique, Troisième édition. Montréal: Les Presses de l'Université de Montréal; 2003. p. 779.

5. Moffitt TE, Caspi A. Childhood predictors differentiate lifecourse persistent and adolescence-limited antisocial pathways among males and females. Dev Psychopathol. 2001; 13: $355-75$.

6. Sroufe LA. Attachment and development: A prospective, longitudinal study from birth to adulthood. Attach Hum Dev. 2005; $7:$ 349-67.

7. Bowlby J. Attachment. 2 ed. In: Attachment and Loss. V. 1. New York: Basic Books; 1982.

8. Ainsworth MDS, Bowlby J. An Ethological approach to personality development. Am Psychol. 1991; 46: 333-41.
9. Juffer F, van IJzendoorn MH, Bakermans-Kranenburg MJ. Attachment-based interventions in early childhood: an overview. In: Juffer F, Bakermans-Kranenburg MJ, van IJzendoorn $\mathrm{MH}$, editors. Promoting positive parenting: an attachment-based intervention. New York: Taylor \& Francis Group/Lawrence Erlbaum Associates; 2008. p. 37-57.

10. De Wolff M, van IJzendoorn MH. Sensitivity and attachment: a meta-analysis on parental antecedents of infant attachment. Child Dev. 1997; 68: 571-91.

11. Belsky J. Parental and nonparental child care and children's socioemotional development: a decade in review. J Marriage Fam. 1990; 52: 885-903.

12. Ainsworth MDS, Blehar M, Waters E, Wall S. Patterns of attachment: a psychological study of the strange situation. Hillsdale: Lawrence Erlbaum Associates; 1978.

13. Van IJzendoorn MH, Schuengel C, Bakermans-Kranenburg MJ. Disorganized attachment in early childhood: metaanalysis of precursors, concomitants, and sequelae. Dev Psychopathol. 1999; 11: 225-49.

14. Bakermans-Kranenburg MJ, van Ijzendoorn MH, Juffer F. Less is more: Meta-analyses of sensitivity and attachment interventions in early childhood. Psychol Bull. 2003; 129: 195-215. 
15. Van den Boom DC. The influence of temperament and mothering on attachment and exploration: an experimenta manipulation of sensitive responsiveness among lowerclass mothers with irritable infants. Child Dev. 1994; 65: 1457-77.

16. Paquette D, Bigras $M$. The risky situation: a procedure for assessing the father-child activation relationship. In Newland LA, Freeman HS, Coyl DD, editor. Emerging topics on father attachment: considerations in theory, context and development. London: Routledge; 2010.
17. Witt PL, Wheeless LR, Allen MA. Meta-analytical review of the relationship between teacher immediacy and student learning. Commun Monogr. 2004; 71: 184-207.

18. Martin DJ, Garske JP, Davis MK. Relation of the therapeutic alliance with outcome and other variables: a metaanalytic review. J Consult Clin Psychol. 2000; 68: 438-50.

19. Greenman PS, Tardif, G. From the cradle to the grave: the clinical applications of attachment theory throughout the lifespan. In: Columbus AM, editor. Advances in Psychology Research, Nova science Publishers, Inc. 62: 2009.

Recebido em 12 de julho de 2010

Versão final apresentada em 15 de outubro de 2010

Aprovado em 29 de outubro de 2010 